\title{
ПІДВИЩЕННЯ ЕНЕРГЕТИЧНОЇ ЕФЕКТИВНОСТІ КОЛІСНИХ МАШИН МЕТОДОМ ВІДКЛЮЧЕННЯ ЦИЛІНДРІВ В АВТОТРАКТОРНОМУ ДВИГУНІ
}

\begin{abstract}
Харківський національний автомобільно-дорожній університет
В статmі запропоновано алгоритм вибору кількості відключених циліндрів в залежності від миттєвого значення потужності. При використанні запропонованого способу управління енергетичною ефективністю автотракторного двигуна при роботі з неповним навантаженням програма бортового комп'ютера з фрактичної потужності, визначає необхідне для роботи двигуна мінімальне число працюючих циліндрів. Отримано залежність ККД колісної машини від миттєвої реалізованої потужності шляхом обробки записів бортового реєстратора параметрів руху та побудовано апроксимацію отриманої дослідним шляхом залежності ККД автотракторного двигуна від коефіцієнта використання потужності методом найменших квадратів. До питання про те, скільки найвигідніше відключити циліндрів двигуна, для ефрективного використання його потужності на колишньому рівні без необхідності збільшення циклової подачі палива. При більшій цикловій подачі в циліндрах збільшується середній індикаторний тиск і поліпшується процес згоряння. При відключенні частини циліндрів двигуна в процесі його роботи індикаторна потужність двигуна зменшується, в результаті чого знижується частота обертання колінчастого вала і крутний момент двигуна. Представлено енергетичну діаграму колісної машини в номінальному режимі при русі з дизельним двигуном. Вона показує, що витрати на власні потреби становлять 30-40 \%. Необхідність підвищення ефрективності роботи двигуна в широкому діапазоні швидкісних і навантажувальних режимів сприяє як пошуку нових технічних рішень, так і розвитку раніше відомих, які добре себе зарекомендували. Це пов'язано в першу чергу з вимогами до паливної економічності та токсичності відпрацьованих газів, а в низці випадків з необхідністю поліпшення перехідних процесів у двигуні із збереженням інших характеристик на колишньому рівні чи навіть їх покращення.
\end{abstract}

Ключові слова: колісна машина, енергетична ефективність, відключення циліндрів, автотракторний двигун, коефіцієнт корисної дії, коефріцієнт використання потужності.

\section{Вступ}

Проблема раціонального використання доступної потужності автотракторного двигуна при легкому профілі шляху і невеликій швидкості руху для неповновагових і порожніх колісних машин неодноразово піднімалася у зв'язку з вантажними перевезеннями [1-5, 6, 8 та ін.].

Лише 4-5 \% тривалості тягового режиму [7] реалізується з потужністю, близькою до номінальної, 70-75\% - 3 навантаженнями 0,5-0,8 номінальної, решту часу використання сили тяги і потужності колісних машин не перевищує 0,5 номінальних значень. Таким чином, зростаюча потужність автотракторних двигунів посилює проблему іiї повної реалізації в експлуатації, а отже, і проблему підвищення експлуатаційного ККД тягового режиму руху.

Було встановлено [3-7], що одним із способів підвищення енергетичної ефективності є часткове відключення циліндрів (або циклів) автотракторного двигуна в періоди роботи 3 явним перевищенням його сили тяги і потужності.

Одним 3 перших енергетичних підходів до оцінки ефективності автомобіля запропонував П.М. Гащук [1]. Цей підхід отримав свій розвиток в роботах П. П. Евсеєва [2]. Слід зазначити також 3 іноземних джерел роботу Ю. Мацкерле [3]. Поява нових, альтернативних ДВ3 енергоустановок (електричні двигуни, водневі ДВ3, гібридні енергоустановки і т. п.), джерел енергії (акумуляторів, маховиків) [4-6] призвела до необхідності розширення поняття (експлуатаційної властивості) «паливна економічність», включенням до нього витрати не тільки теплової енергії палива, а й енергії інших видів (електричної та механічної).

Метою цього дослідження $є$ визначення раціональної кількості відключених циліндрів в автотракторному двигуні для підвищення енергетичної ефективності колісних машин.

Для досягнення зазначеної мети необхідно вирішити такі задачі:

- представити енергетичну діаграму колісної машини в номінальному режимі при русі 3 дизельним двигуном;

- шляхом обробки записів бортового реєстратора параметрів руху отримати залежність ККД колісної машини від миттєвої реалізованої потужності та побудувати її апроксимацію; 
- запропонувати алгоритм вибору кількості відключених циліндрів в залежності від миттєвого значення потужності.

\section{Визначення раціональної кількості відключених циліндрів в автотракторному двигуні для підвищення енергетичної ефективності колісних машин}

Діапазон зміни ККД в режимі тяги охоплює значення від 0,2 до 0,42 . Чисельні значення ККД (рис. 1) [9] функціонально залежать від значень дотичної сили тяги, швидкості руху та потужності, що реалізується на ободах рушійних коліс, яка дорівнює добутку сили тяги на швидкість. Із збільшенням сили тяги, швидкості і потужності підвищується ефективність перетворення енергії. Оптимальним ККД є використання потужності в діапазоні від 0,35 до 0,40 тривалого режиму роботи колісної машини.

ККД колісної машини може бути представлений як

$$
\eta_{\text {к. м. }}=\frac{P_{\text {кор }}}{P_{\text {вит }}}=\frac{P_{\text {т }}}{P_{\text {т }}+P_{\text {втр }}+P_{\text {вл. пот. }}},
$$

де $P_{\text {кор }}$ - корисна потужність; $P_{\text {вит }}$ - витрачена потужність; $P_{\text {т }}$ - потужність на тягу колісної машини; $P_{\text {втр }}-$ потужність втрат; $P_{\text {вл. пот. }}-$ потужність, що витрачається на власні потреби.

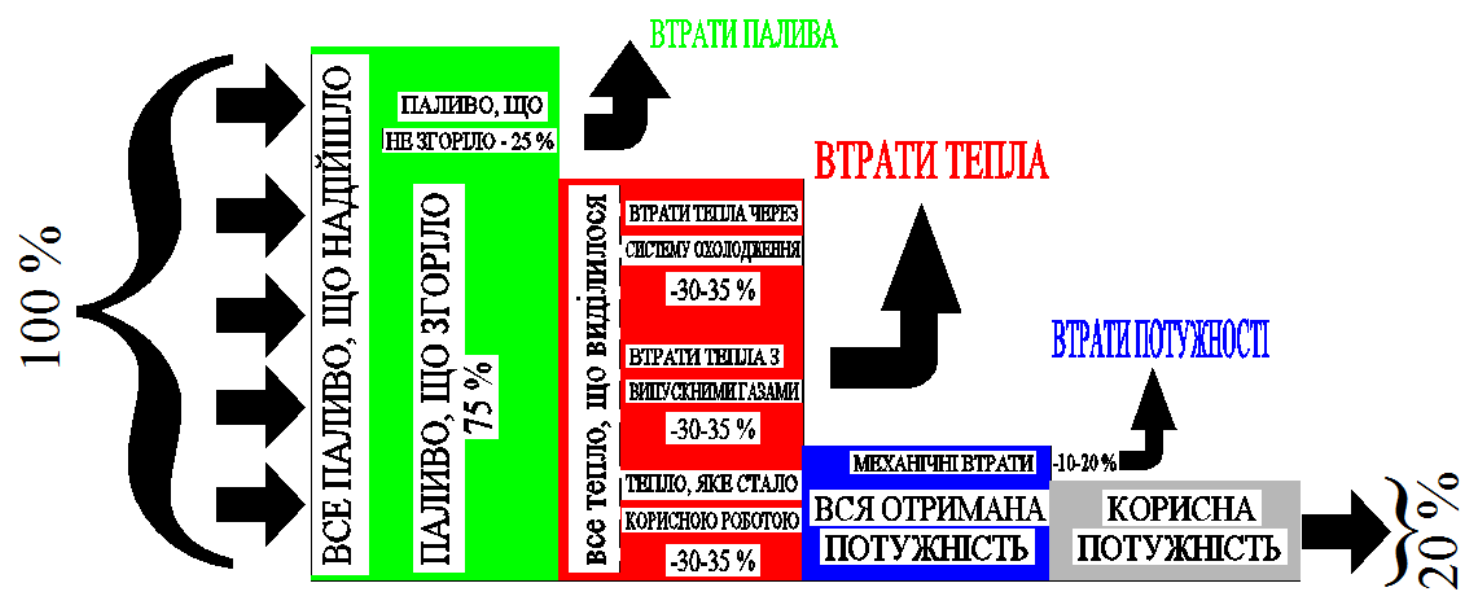

Рис. 1. Структура розподілу втрат в ДВ3

Потужність на тягу колісної машини

$$
P_{\mathrm{T}}=F_{\mathrm{K}} \cdot V_{\mathrm{a}},
$$

де $F_{\text {к }}$ - сила тяги на колесі колісної машини, кН; $V_{\text {a }}$ - швидкість руху, м/с.

Енергетична діаграма колісної машини в номінальному режимі при русі з дизельним двигуном показана на рис. 2.

Видно, що витрати на власні потреби $P$ становлять 30-40\%. Потужність, що витрачається колісної машиною на власні потреби, оптимізована за рахунок застосування регульованого допоміжного приводу.

Потужність втрат $P_{\text {втр }}$ складається з механічних, енергетичних і втрат на насосні ходи і привід допоміжного обладнання. Ці втрати оцінені з використанням технічної документації.

Шляхом обробки записів бортового реєстратора параметрів руху отримано залежність ККД колісної машини від миттєвої реалізованої потужності. На рис. 3 показано залежність ККД автотракторного двигуна від коефіцієнта використання потужності (КВП), рівного відношенню миттєвої потужності колісної машини до його номінальної потужності. Тут відображено роботу всієї системи перетворення теплоенергії, механічні втрати, а також витрати на власні потреби. Можна сказати, що це результат багаторазово повтореного натурного експерименту, умови якого визначені режимами експлуатації.

Побудовано апроксимацію отриманої дослідним шляхом залежності ККД автотракторного двигуна $\eta$ від коефіцієнта використання потужності методом найменших квадратів у вигляді

$$
\eta=\frac{\gamma}{a \gamma+b}
$$


У результаті ККД автотракторного двигуна в номінальному режимі становить 25-40 \%.

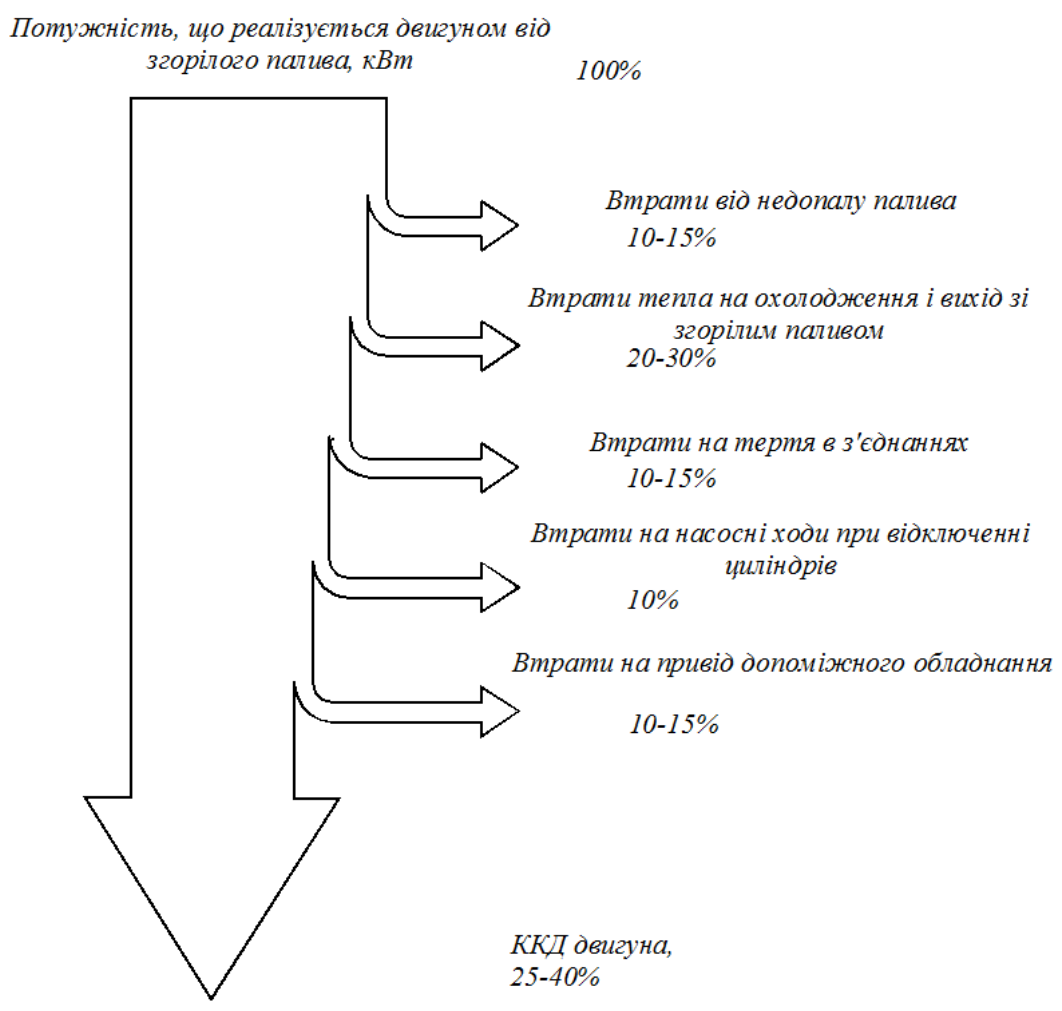

Потужність, цо реалізується на тягу, кВт

Рис. 2. Енергетична діаграма колісної машини в номінальному режимі при використанні дизельного двигуна

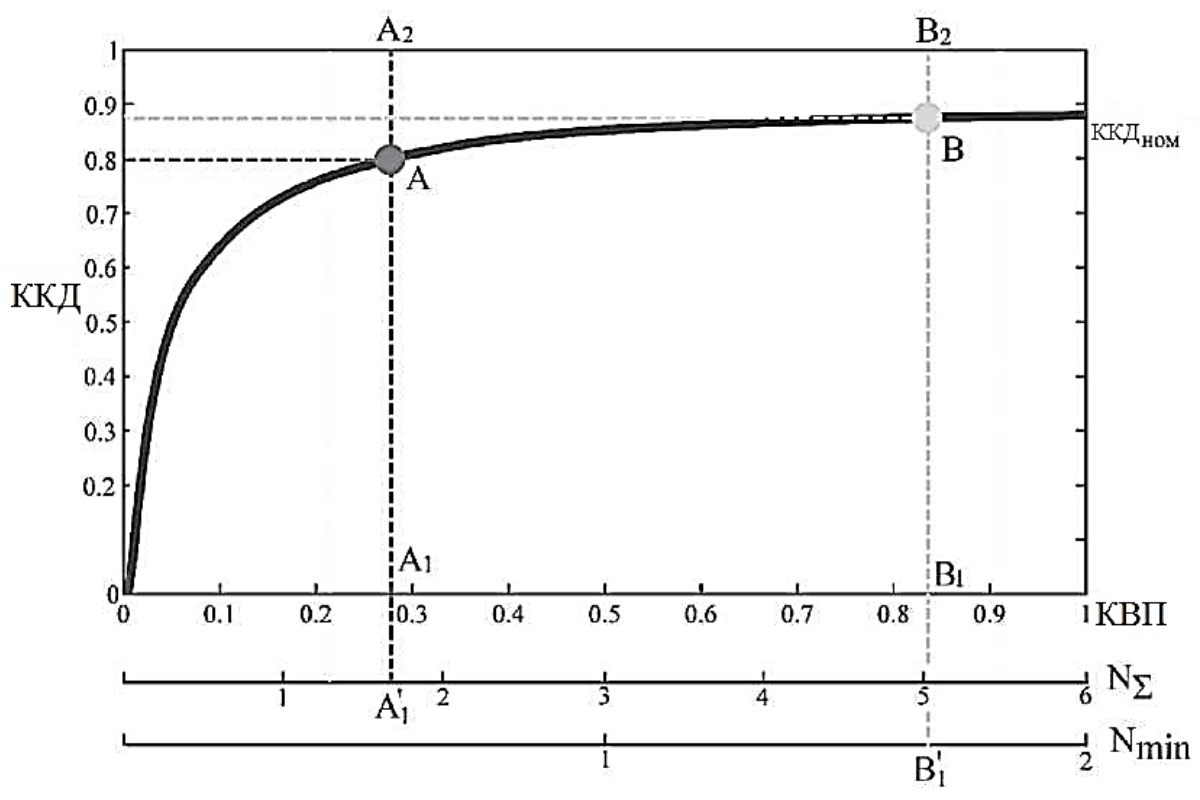

Рис. 3. ККД автотракторного двигуна в залежності від КВП в режимі тяги

Пропонується такий алгоритм (рис. 4) вибору кількості відключених циліндрів в залежності від миттєвого значення потужності.

Оскільки в автотракторному двигуні є можливість регулювання сили тяги, питання оперативного відключення/підключення одного або декількох циліндрів в автоматичному режимі може бути вирішене на верхньому рівні системи управління.

Двигун з відключеним циліндром можна використовувати для знаходження лінійної швидкості колісної машини, що збільшить ефективність роботи протибуксувальної системи і дозволить максимально реалізувати його тягові властивості. 


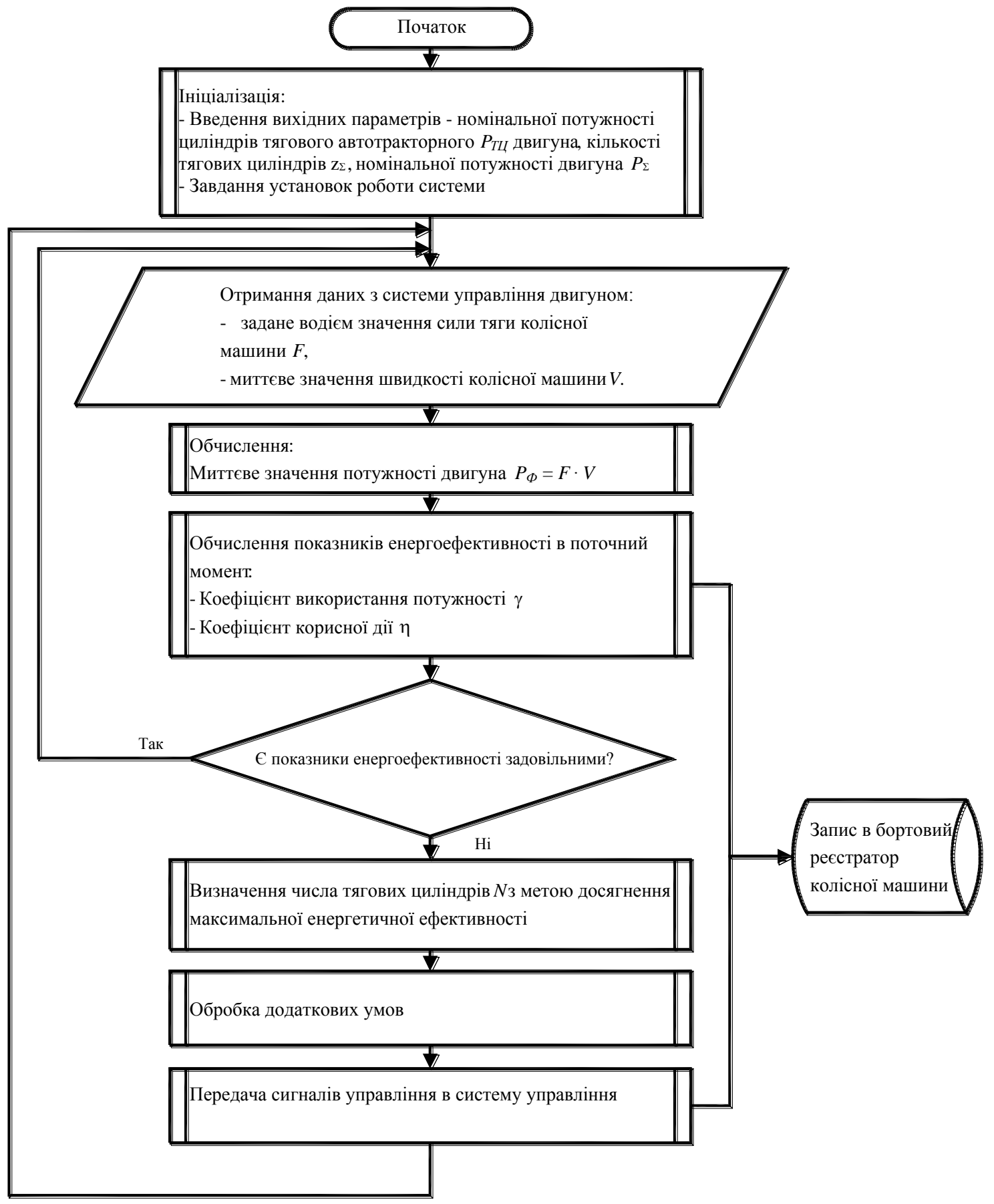

Рис. 4. Алгоритм регулювання потужності і числа відключених циліндрів

Число циліндрів автотракторного двигуна в загальному випадку позначимо як $z_{\Sigma}$ (див. рис. 3), в даному випадку $z_{\Sigma}=8$. Номінальну потужність одного тягового циліндра позначимо як $P_{\text {тц }}$, візьмемо $P_{\text {тц }}=19,3$ кВт. Тоді повна номінальна потужність двигуна складе $P_{\Sigma}=z_{\Sigma} \cdot P_{\text {ТЦ }}=8 \cdot 19,3=154,5$ кВт.

Припустимо, що в деякий момент часу потужність, яка фактично витрачається автотракторним двигуном на тягу при роботі всіх циліндрів, становить $P_{\Phi}$, наприклад, $P_{\Phi}=43$ кВт. У цьому випадку КВП колісної машиною складе

$$
\gamma_{\Sigma}=O A_{1}=\frac{P_{\Phi}}{P_{\Sigma}}=\frac{43}{154,5}=0,278,
$$

цьому режиму відповідає експлуатаційний ККД автотракторного двигуна (див. рис. 3). 
При використанні запропонованого способу управління енергетичною ефективністю автотракторного двигуна при роботі 3 неповним навантаженням програма бортового комп'ютера 3 фактичної потужності $P_{\Phi}$ визначає необхідне для роботи двигуна мінімальне число працюючих циліндрів $z_{\min }$, в даному випадку це число дорівнює двом (мінімально можливе), $z_{\min }=3$, i відключає інші тягові циліндри. У цьому випадку потужність двигуна складе $P_{\min }=z_{\min } \cdot P_{\mathrm{ТЦ}}=3 \cdot 19,3=57,9$ кВт.

Значення КВП в даному режимі - при роботі двох тягових циліндрів - складе

$$
\gamma_{\min }=O B_{1}=\frac{P_{\Phi}}{P_{\min }}=\frac{43}{57,9}=0,742 .
$$

Таким чином, при визначенні коефіцієнта використання потужності можемо судити про значення ККД автотракторного двигуна.

\section{Висновки}

1. Представлено енергетичну діаграму колісної машини в номінальному режимі при русі з дизельним двигуном. Вона показує, що витрати на власні потреби становлять 30-40\%. Потужність, що витрачається колісною машиною на власні потреби, оптимізована за рахунок застосування регульованого допоміжного приводу.

2. Отримано залежність ККД колісної машини від миттєвої реалізованої потужності шляхом обробки записів бортового реєстратора параметрів руху та побудовано апроксимацію отриманої дослідним шляхом залежності ККД автотракторного двигуна від коефіцієнта використання потужності методом найменших квадратів.

3. Запропоновано алгоритм вибору кількості відключених циліндрів в залежності від миттєвого значення потужності. При використанні запропонованого способу управління енергетичною ефективністю автотракторного двигуна при роботі з неповним навантаженням програма бортового комп'ютера 3 фактичної потужності, визначає необхідне для роботи двигуна мінімальне число працюючих циліндрів.

\section{СПИСОК ВИКОРИСТАНОÏ ЛІТЕРАТУРИ}

[1] П. Н. Гащук, Энергетическая эффективность автомобиля. Львов, Україна: Свет, 1992. 208 с.

[2] П. П. Евсеев, Некоторые вопросы энергетики автомобиля. Киев, Україна: Викол, 2006. 236 с.

[3] Ю. Мацкерле, Современный экономичный автомобиль. Пер. с чешск. В.Б. Иванова: под. ред. А.Р. Бендикова. М., Россия: Машиностроение, 1987.320 с.

[4] О. В. Бажинов, О. П. Смирнов, С. А. Серіков та ін., Синергетичний автомобіль. Теорія і практика. Харків, Україна: ХНАДУ, $2011.236 \mathrm{c}$

[5] О. В. Бажинов, О. П. Смирнов, С. А. Серіков, та ін., Гібридні автомобілі. Харків, Україна: ХНАДУ, 2008. 327 с.

[6] М. А. Подригало, Д. В. Абрамов, Ю. В. Тарасов, В. М. Ефимчук, «Энергетическая экономичность автомобиля и критерии её оценки,» Вісник національного технічного університету «ХПІ». Збірник наукових праць. Серія: Автомобіле- та тракторобудування. № 40 (1119), с. 28-37. 2015.

[7] А. А. Молодан, А. С. Полянский, «Теоретические расчеты относительного дополнительного расхода топлива при отключении цилиндров,» Інженерія природокористування, № 2 (10), с. 14-18. 2018.

[8] М. А. Подригало, Н.П.Артёмов, Д.В.Абрамов, М. Л. Шуляк, «Оценка дополнительных энергетических потер при установившемся режиме движения транспортно-тяговых машин,» Вісник національного технічного університету «ХПI». 3бірник наукових пращь. Серія: Автомобіле- та тракторобудування, № 9 (1118), с. 98-107. 2015.

[9] P. G. Kolpahchyan, A. A. Zarifyan (Jr), "Study of the asynchronous traction drive's operating modes by computer simulation. Problem formulation and computer model," Transp. Prob. Int. Sci. J, vol. 10, is. 2, pp. 125-136. 2015.

Молодан Андрій Олександрович - канд. техн. наук, доцент, доцент кафедри технології машинобудування і ремонту машин, e-mail: tmirm@ukr.net.

Харківський національний автомобільно-дорожній університет, м. Харків. 
A. Molodan

\title{
Increasing energy efficiency of wheel machines method of disconnecting cylinders in a vehicle engine
}

\author{
Kharkiv National Automobile and Highway University
}

\begin{abstract}
The article proposes an algorithm for selecting the number of disconnected cylinders, depending on the instantaneous value of power. When using the proposed method of controlling the energy efficiency of the tractor motor when working with incomplete load program on-board computer of the actual power, determines the required for the engine to work minimum number of cylinders. The dependence of the wheel machine efficiency on the instantaneous realized power was obtained by processing the records of the onboard motion logger and the approximation obtained by the experimental dependence of the efficiency of the motor tractor on the coefficient of power utilization by the least squares method was obtained. To the question of how much it is most advantageous to turn off the engine cylinders, to effectively use its power at the same level without the need to increase the cycle fuel supply. With a larger cycle supply in the cylinders, the average indicator pressure increases and the combustion process improves. When the part of the cylinder of the engine is switched off during its operation, the indicator power of the engine decreases, resulting in a decrease in the crankshaft rotation speed and engine torque. The energy diagram of a wheeled car in nominal mode when driving with a diesel engine is presented. It shows that the cost of own use is $30-40 \%$. The need to increase the efficiency of the engine in a wide range of speed and load modes contributes to the search for new technical solutions and the development of previously known, which have proven themselves. This is due in the first place to the requirements for fuel economy and toxicity of the exhaust gas, and in some cases the need to improve the transients in the engine while maintaining other characteristics at the same level or even improving them.
\end{abstract}

Key words: wheeled vehicle, energy efficiency, cylinder shutdown, tractor engine, efficiency, power utilization.

Molodan Andrii - Ph. D. (Eng.), Associate Professor, Associate Professor of the Department of Mechanical Engineering Technology and Machine Repair, e-mail: tmirm@ukr.net.

А. А. Молодан

\section{Повышение энергетической эффективности колесных машин методом отключения цилиндров в автотракторном двигателе}

\author{
Харьковский национальный автомобильно-дорожный университет
}

В статье предложен алгоритм выбора количества отключенных цилиндров в зависимости от мгновенного значения мощности. При использовании предлагаемого способа управления энергетической эффрективностью автотракторного двигателя при работе с неполной нагрузкой программа бортового компьютера из фрактической мощности, определяет необходимое для работы двигателя минимальное число работающих цилиндров. Получена зависимость КПД колесной машины от мгновенной реализованной мощности путем обработки записей бортового регистратора параметров движения и построена аппроксимация полученной опытным путем зависимости КПД автотракторного двигателя от коэффициента использования мощности методом наименьших квадратов. $K$ вопросу о том, сколько выгоднее отключить иилиндров двигателя, для эфффективного использования его мощности на прежнем уровне без необходимости увеличения цикловой подачи топлива. При большей цикловой подачи в цилиндрах увеличивается средний индикаторный давление и улучшается процесс сгорания. При отключении части цилиндров двигателя в процессе его работы индикаторная мощность двигателя уменьшается, в результате чего снижается частота вращения коленчатого вала и крутящий момент двигателя. Представлено энергетическую диаграмму колесной машины в номинальном режиме при движении с дизельным двигателем. Она показывает, что расходы на собственные нужды составляют 30-40 \%. Необходимость повышения эфорективности работы двигателя в широком диапазоне скоростных и нагрузочных режимов способствует как поиску новых технических решений, так и развития ранее известных, хорошо зарекомендовавших себя. Это связано в первую очередь с требованиями к топливной экономичности и токсичности отработавших газов, а в ряде случаев с необходимостью улучшения переходных процессов в двигателе с сохранением других характеристик на прежнем уровне или даже их улучшение.

Ключевые слова: колесная машина, энергетическая эффективность, отключение цилиндров, автотракторный двигатель, коэфффициент полезного действия, коэффиццент использования мощности.

Молодан Андрей Александрович - канд. техн. наук, доцент, доцент кафедры технологии машиностроения и ремонта машин, e-mail: tmirm@ukr.net. 